\title{
Changing building user attitude and organisational policy towards sustainable resource use in healthcare
}

Article

Accepted Version

Gulliver, S., Grzybek, H., Radosavljevic, M. and Wiafe, I. (2013) Changing building user attitude and organisational policy towards sustainable resource use in healthcare. Health Policy and Technology, 2 (2). pp. 75-84. ISSN 2211-8837 doi: https://doi.org/10.1016/j.hlpt.2013.03.006 Available at https://centaur.reading.ac.uk/31605/

It is advisable to refer to the publisher's version if you intend to cite from the work. See Guidance on citing.

To link to this article DOI: http://dx.doi.org/10.1016/j.hlpt.2013.03.006

Publisher: Elsevier

All outputs in CentAUR are protected by Intellectual Property Rights law, including copyright law. Copyright and IPR is retained by the creators or other copyright holders. Terms and conditions for use of this material are defined in the End User Agreement.

www.reading.ac.uk/centaur 
Central Archive at the University of Reading

Reading's research outputs online 


\title{
Changing Building User Attitude and Organisational Policy towards Sustainable Resource use in healthcare
}

\begin{abstract}
Health care provision is significantly impacted by the ability of the health providers to engineer a viable healthcare space to support care stakeholders needs. In this paper we discuss and propose use of organisational semiotics as a set of methods to link stakeholders to systems, which allows us to capture clinician activity, information transfer, and building use; which in tern allows us to define the value of specific systems in the care environment to specific stakeholders and the dependence between systems in a care space. We suggest use of a semantically enhanced building information model (BIM) to support the linking of clinician activity to the physical resource objects and space; and facilitate the capture of quantifiable data, over time, concerning resource use by key stakeholders. Finally we argue for the inclusion of appropriate stakeholder feedback and persuasive mechanism, to incentivise building user behaviour to support organisational level sustainability policy.
\end{abstract}

\section{Keywords}

Health, Sustainability, Semiotics, BIM, Behaviour, Persuasion 


\section{INTRODUCTION}

The built environment provides healthcare providers the physical infrastructure, which is used to support health interaction and care. Space provides the context within which health services are constructed; thus the built environment significantly impacts facilitation of user needs. Health spaces, however, are dependent upon, and or constrained by, the limitations of physical space and the defined policies of the organisation. Accordingly, appropriate appreciation of the physical space is crucial if a total health-care policy strategy is to be created support interaction and alignment between the built space, occupant activity, and quality care delivery.

'Pervasive' is an adjective of the root 'pervade', which implies the spreading throughout. Pervasive informatics is the study of information in environments where information is, or can be, pervasive; and in context of this paper is an interdisciplinary area of research focussing on how information about the building, and care information concerning health provision can be brought together to support sustainable care activity.

In section 2 we consider common building assessment methods, and demonstrate how existing methods largely ignore stakeholder and organisational activity. In section 3 we introduce the notion of Key Performance Indicators (KPIs), and benchmarking, in context of building energy management. In section 4 we show how semiotic methods might be used to define critical health systems, and how stakeholder-focused KIP can be defined. In sections 5 and 6 we discuss how information can be provided back to users; briefly considering how a 
semantic building information model might be used to support persuasive feedback, motivation mechanisms and organisational policy change. In section 7 we conclude the paper by discussing how inclusion of activity management is critical to the effective implementation of pervasive informatics, and the development of a sustainable total health-care policy strategy.

\section{SUSTAINABILITY AND BUILDING PERFORMANCE}

\subsection{Defining Sustainability.}

Organisational durability is the ability to resist against change. Organisational sustainability is the ability to embrace change by engaging in renewal, maintenance, and managed sustenance. At a time when UK healthcare resource allocation is being shifted to respond to mounting pressures (i.e. alleged UK government spending cuts of 20 billion; an aging population, increased level of chronic diseases such as diabetes, recent reports $\{$ e.g. the Dilnot report\}, increasing concerns over future provision of healthcare for the elderly; everchanging public expectation of NHS care, impacting attitudes towards rights to care provision and compensation; and carbon-emission regulation that risks NHS resources being spent on management of carbon emission instead of care), it is clear that adoption of durability policies, without consideration of sustainability, is not a viable long-term strategy. In order to obtain true sustainability, however, we must be able to dynamically consider how pervasive information (i.e. information concerning health space, the patient and care and information needs) can best be brought together to support and embrace change. In section 2.2 we consider 
the traditional view of building sustainability. In section 2.3, we define a need to expand this narrow definition; with a particular need in health to incorporate care and health activities, thus allowing us to consider activity and quality benchmarking as part of the sustainability definition.

\subsection{Current Perception of Sustainability}

The term sustainability is commonly, and traditionally, assumed to mean 'building energy sustainability'. Despite a vision to provide 'low carbon quality healthcare environments that are sustainable, resilient, and safeguards of high quality patient care' [1], each year NHS buildings consume over $£ 410$ million worth of energy, and produces 3.7 million tones of $\mathrm{CO} 2$. As well as energy use being financially costly, looming carbon taxes are increasingly threatening a shift in NHS resources, which offer no health benefit to patient care or clinician activities. For example, under the rules of the 'Energy Performance of Buildings Regulations', all NHS buildings with a capacity greater than $1,000 \mathrm{~m} 2$ must clearly display a 'Display Energy Certificate' [2], which provides a summary of building performance efficiency - however such policy is not linked in any way to patient care.

The term "building energy performance", however, means different things to different stakeholders [3]. When aiming to assess the environmental impact of a building there is no uniform internationally adopted way of assessing how sustainable a building performs; which implies that building performance assessment depends greatly upon the assessment method being used. 
A number of building performance assessment methods (sometimes referred to as green building rating methods or environmental assessment tools) have been developed [4]. The first significant attempt to create a comprehensive method of assessing a wide range of environmental considerations in buildings was BREEAM (the Building Research Establishment Environmental Assessment Method). BREEAM, established in the UK in 1990, was the first commercially available environmental assessment tool for buildings, and still remains a big player in building assessment. For example, the way energy is used to provide heating, lighting and power in NHS buildings is subject to BREEAM Healthcare $\mathrm{B}(4) \mathrm{H}$ [5]. Building performance assessment methods can be crudely split into two categories: i) those based on criteria and weighting systems - e.g. BREEAM (UK); or ii) those that use a checklist of building performance aspects - e.g. LEED (US). Many assessment schemes make use of a weighting scheme as it captures the importance of different performance aspects relative to others. However, there is no consensus on the method or suitable guidelines to help assign these weightings.

The use of assessment performance method provides within care building, e.g. BREEAM Healthcare $\mathrm{B}(4) \mathrm{H}$ [5], provides useful information about building fabric [6], however such performance assessment fails to consider sustainability in the context of building type, location and/or use (i.e. the social, cultural and organisational aspects of the building). It is the aim of regulators that NHS operations will be increasingly accountable to open scrutiny. So public reporting concerning efficiency, sustainability and carbon reduction will increasingly impact 
operational policy, becoming the norm; however assessment of health space without analysis being placed in context of health activity seems nonsensical.

The currently narrow view of sustainability in construction, which primarily focuses on 'energy use of buildings' ignores the clearly wider resource management issues that exists in all health organisations (i.e. Patient safety, staff allocation and care, quality of life, etc). Moreover consideration of energy alone in context of building structure and fabric fails to link resource allocation to user activity in space; and ultimately the impact that this has, in care buildings, to resource use and patient care quality. To achieve effective change management, in both building structure, organisational policy and user activity, we first require information about the use of space and its care function, in order to justify and change towards a more generic definition of sustainability; which is the ability to embrace change by engaging in renewal, maintenance, and managed sustenance.

\subsection{Incorporating the User in the Sustainability definition}

NHS Energy Performance of Building Regulations was reviewed in 2010, and a $25 \%$ improvement target on all energy consumption for all new builds and refurbishments was set [7]. This approach, however, focuses on the development of new builds, which seems nonsensical when (unless NHS policy shifts significantly) $70 \%$ of buildings used in the provision of healthcare in 2050 have already been built [8]; which means such regulation will have a limited impact on NHS energy consumption. Resource sustainability within existing buildings, 
particularly older public buildings, is harder to achieve; since it is necessary to live with existing deficiencies, and / or justify modernisation. However, achieving even minor improvements in the sustainability of activity within health buildings could have a significant impact on energy consumption [9]. The sum of energy used during the lifetime of a building, relates to the energy used during construction, the operational usage, and the final energy required to demolish it. Since operational energy relates to approximately $80 \%$ of lifetime energy use, any improvement in energy and resource management, particularly within existing building, would significantly reduce the building's long-term energy consumption; and hence contribute towards a more efficient health economy. Although discussion so far has focused on the traditional 'energy' definition of sustainability, health providers should consider consideration of all resources, to develop a more appropriate platform for efficiency and sustainability improvement.

Improvement in resource management, i.e. of any resource, however, can only be efficiently achieved if building use is optimised in context of building activity; which implies customisation of building facilities and activity processes to maximise resource use. A healthcare building, as implied above, is a complex web of socio-technical systems, yet users currently have limited means of determining how activity impacts general sustainability. To facilitate long-term sustainability in health buildings, assessment must be able to monitor impact of activity use over time, in order to determine and support positive behaviour change. 


\section{KEY PERFORMANCE INDICATORS}

It is often too time consuming, or impractical, to assess everything that is measureable within a health care building, yet it is important to measure Key Performance indicators (KPI). KPls vary significantly, i.e. depending on a building's location, climate, government legislation and policy, and usage. Building performance assessment methods, therefore, should identify building specific KPI, which support the building and organisational on-going strategic and sustainability goals; whether that relates to energy, health or quality organisational concerns. KPI's are therefore the variables that most significantly impact a particular building, performing its organisational function. Building KPIs must be quantifiable measurements, to facilitate target setting and benchmarking within the organisation [16], which plays a critical role in underpinning performance and quality review [4]. Examples of health $\mathrm{KPI}$, which are influenced by either building space/fabric, and/or resource, allocation include: Hospital bed occupancy rate, Number of hospital acquired infections in specific wards, ER waiting time, Lab turnaround time, etc.

The occupants of the building often best understand contextual building use and performance, however very few organisations actually ask their staff whether the building meets functional requirements; or how total sustainability might be achieved. Environmental assessment, instead of relying on fabric focussed perspectives, should consider the real-world relationship between the building and its true stakeholders; which in the case of health buildings relates to 
a range of stakeholders, including patients and clinicians. Analyses of social, cultural and organisational dimensions are, however, regularly ignored; as consideration of the user dimension is perceived as being 'complex'. Historically, user needs have been captured as an inflexible set of formalised requirements for use with benchmarking. With a growing appreciation of socially defined environments, however, which allows multiple functions and purposes to be supported through complex socio-technical systems, organisations are starting to appreciate that it is important to use appropriate socio-technical methods to capture information from, and pass information back to, stakeholders at all stages of the activity lifecycle. In the case of healthcare, this implies that the building should to support information provision within the healthcare pathway, and should positively shift care pathway design, care activity of clinicians, and general organisational policy towards generic sustainability; to maximise the potential output from limited resource.

A durability strategy in healthcare policy definition focuses on monitoring and regulating activity. Although this can be hugely beneficial for resource 'saving', it encourages unilateral information transfer (i.e. the capture, but not sharing of information), and often negatively binds health care provision within the resource allocation of bureaucracy. Sustainability strategies aim to embrace changes to resource allocation by engaging renewal, maintenance, and managed sustenance. Instead of forcing change via regulation, sustainable resource management encourages a unidirectional flow of information that allows users of resource to identify their resource use and self-manage change. By 
effectively informing all stakeholders of how their activity impacts resource use, patient safety and quality metrics, and by manipulating motivation via effective incentives and policy change, a positive attitude toward change can be encouraged. To achieve this ideal, in this paper we propose the use of organisational semiotics in combination with a building information model.

\section{ORGANISATIONAL SEMIOTICS}

Semiotics, the science of signs, is considered as an important discipline for understanding information and communication [17]. The word "semiotics" originates from the Greek word "symptom", from the study of medical signs; yet has become a means of understanding the world as a system of relations of "signs". A sign is anything that stands for something else (i.e. any signal, sound, natural object or artefact), with semiotics being defined as a formal doctrine of signs. Ferdinand de Saussure (1857-1913) and Charles Sanders Peirce (18391914) ran independent investigations into the relation between knowledge and signs [29]. Their combined work developed the basis for semiotics, the "doctrine of signs", which aims to look into the "life of sign in society".

Peirce originally conceived of three distinct fields of semiotics, known as syntactic, semantics and pragmatics, which combine to study the properties and

the use of specific signs. To these three headings, Stamper [21] added three more, empirics, physical world and social world. Although his work has been widely used in analysing business organisation and design information systems, 
its relevance can be seen clearly in designing building and resource management (Figure 2).

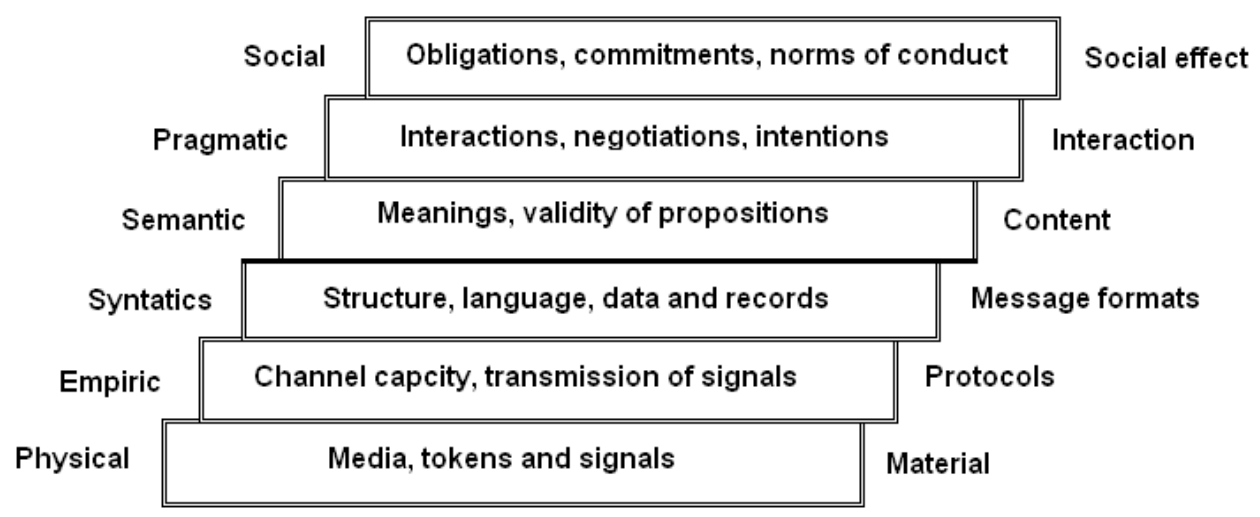

Figure 2. Applying the semiotic framework in studying buildings (based on Stamper (1973)).

As well as being constructs that serve physical and economic purposes, health buildings clearly incorporate a complex set of functional and social messages as signs. Although functional requirements can be captured using conventional requirement techniques, non-functional and social requirements are often difficult to specify, despite their considerable importance to pervasive activities. As health space is based on relationships, which are social constructs, studying a building from a semiotic perspective facilitates improvements in our understanding of how the building provides both formal, informal and social signs to users; thus supporting the capture of, and design for, users' needs.

Organisational semiotics [19] [20] is a sub-branch of semiotics applied to the study of the information used for communication and coordinated activities. Organisational Semiotics (OS) is the study of organisations using semiotics concepts and methods, and considers organisations as an information system 
that is able to process and manage information with the help of people (actors) and supporting information technology. Organisational semiotics (OS) focuses on business and organisations; and can be applied to both public and private organisations. Since organisations have both technical and human factors, it is important to understand the interaction of functions, in order to achieve the organisational goals; since changes in one area can substantively affect each other.

During KPI and requirements collection stages, the semiotic framework (see figure 1) should be used to guide analyst attention to all important aspects of the design. For example, instead of focussing on changing only the physical building (e.g. via an expensive retrofit), consideration of user pragmatic and social activity and interaction should be considered to support change towards sustainability. The bottom three levels relate to the infrastructure of the building. At the physical level, the material used should meet basic functional requirements, e.g. durability, protection and insulation. At the empiric level, the building architecture must meet certain physical and mechanical standards (e.g. capacity, resistance to weight, pressure, etc). At the syntactic level, there may be physical requirements relating to the layout of space, as well as the interior and exterior decoration quality. The top three levels relate to the context and use of space. The semantic level may relate to how layout and decoration affects usability, or in the case of healthcare buildings - patient care. The building provides an environment for the users. The users and the building will establish a mutual dependency. Accordingly, a well-designed building promotes appropriate 
interaction between the building and the users. At the pragmatic level, each part of the building can be designed to transmit intension and affordances. For example, a grand frontage in a hotel can be used to instil the wealth or history of the space to occupants. Paying attention to creating culturally appreciated meaning in design can therefore enhance the interaction relationship between building and users [43]. The social use of a building should also be incorporated into the design of the space, yet should not be difficult to observe; for example, the difference in design between a prison and a hospital is clear. Although both buildings contain bedrooms, eating and living spaces, a prison attempts to emphasise the removal of social and legal rights of inmates, whilst a hospital tries to demonstrate friendliness and hospitality to all patients; as such sociallevel interaction has been shown to positively impact patient recovery.

To support in the eliciting, analysing and specifying of user's requirements, the organisational semiotic community developed a range of methods called MEASUR [18], which relate primarily to the top three upper layers of the semiotic framework (i.e. Social, Pragmatic and Semantic) and consists of the following five methodologies:

a) Problem Articulation Method (PAM), which consists of methods that are applied when the problem definition is unclear [19].

b) Semantic Analysis Method (SAM), which elicits and represents knowledge about the organisations, and formalises the requirements. 
C) Norm Analysis Method (NAM), which allows the capture of general behaviour patterns, by analysing behaviour regularities.

d) Communication and Control Analysis (CCA), which assists in analysing the communications between agents and systems.

e) Meta-Systems Analysis, which considers the meta-problem in planning and project management.

In this paper we propose the use of Problem Articulation Method (PAM) to support the capturing of KPI from stakeholders involved in the operating life of healthcare building. PAM consists of a number of techniques that can help to plan and manage complex technical projects, thus assisting to reduce the complexity of the system, since the requirements of each unit, i.e. part of modelled organisation, and its contribution to the overall goal can then be more readily analysed. Liu et al. [20] described PAM as comprising of: i) Unit systems definition; ii) Stakeholder Analysis; iii) Collateral structuring; iv) Valuation framing; and v) Organisational containment. We will focus on describing the first four methods, which are deemed as most relevant to building $\mathrm{KPI}$, requirements assessment, and policy definition in healthcare building.

Unit Systems Definition: A unit system is a set of organised activities that consume resources to achieve a defined objective, e.g. HVAC, production, lighting, etc. In the context of health care, a unit system might be any scoped unit, lab, ward or group of care activities, which have definable inputs, processes, 
outputs and feedback mechanism. Liu et al. [20] described how unit systems within a complex project can be described and organised by listing and indenting all sub-systems, i.e. the complexity of considering sustainability in a building can be greatly reduced by first breaking the interaction of systems down into smaller unit and sub-unit systems, e.g. steps in the process. As well as traditional buildings systems, unit system definition can include any functional activity system; allowing systems at all of level of the Semiotic Framework (see Figure 2) to be considered separately.

Stakeholder Analysis: Buildings and activity systems that involve stakeholders with clearly defined characteristics tend to be easier to manage [22]. Therefore, identifying stakeholders and describing their roles, needs and responsibilities is important. The six recognised roles of stakeholders in PAM are [20]: Actors, which has direct influence on the particular building or activity system, e.g. surgeons in a theatre; Client, which is a user who benefits from the outcome of a building or activity system, e.g. patients, carers / family; Provider , who is responsible for providing the conditions and resources to facilitate the predefined deliverable of the building or activity system e.g. porters, administrators; Facilitators are the initiators and enablers of a unit system, and are responsible for directing the team towards objectives and resolving issues of conflict; Governing Bodies that take part in the project planning and management planning of the system. Such governing bodies are responsible for strategic aims, objectives and progress of organisational outcome and are responsible for 
policy definition; Bystanders are participant who do not have to be part of the project but can influence unit system outcomes.

Each stakeholder within a unit system can be prioritised using interaction significance. The results from the stakeholder analysis can be tabulated for each unit or sub-unit system. The outcome should therefore contain the information on each stakeholder's role, job function and responsibility. This can assist in identifying the activities each stakeholder is responsible for, and allows prioritization of requirements. In addition, if required, capture of this stakeholder information can be used, possibly with additional support of Semantic Analysis Method (SAM) or Norm Analysis Method (NAM), to formalise an understanding of dependencies and rules influencing decision making within the care pathway. As required such ontology can be used to redesign care process, to maximise patient safety and resource use.

Collateral Structuring: When the all unit and sub-unit system have been defined, and the roles and responsibilities of the corresponding stakeholders have been articulated, collateral structuring can be used define how systems depend upon each other, and how systems developing, implementation, iteration and maintenance is managed. Collateral structuring identifies related processes and service systems that enable the focal system to function properly, i.e. the external resources and logistics that are required to achieve a functional activity within the unit system. Collateral structuring acts as a check structure to guide organisation as to what resources, i.e. available staff, resources, required skills, 
etc., must be provided before the unit system can function; and what will be the impact if such resource is removed. Accordingly, Collateral Structuring provides a means of recording information required to plan and manage system activity and interactivity, as a whole, and can facilitate the creation of checklists to ensure that all parts of the systems are effectively accounted.

Valuation framing: A thorough assessment of all stakeholders, identified during stakeholder analysis, quantifies the advantages and disadvantages that each stakeholder experience from the unit system. Valuation framing is carried out during stakeholder analysis, since subject matter is similar. The outcome of the exercise should be a tabulated list of clear requirements for each stakeholder. By breaking down value around ten dimensions, defined by Edward Hall as the 'map of culture', valuation framing is able to quantify the quantity and type of value that each stakeholder gains from the unit system. Variables (which include subsistence, classification, territoriality, temporality, learning, recreation, protection, exploitation, association and interation) consider a how stakeholders are positively, or negatively, impacted by the unit system. For example, using valuation framing we should be able to clearly identify, in context of a specific activity, whether introduction of patient records is more benefit to patients, clinician, administrators or management. Results can be used to identify stakeholders whom are most likely to benefit and those that are likely to lose out (in general) from a system; and which of Halls variables most impact stakeholders. Such information is important in understanding the social-technical 
acceptance of key stakeholders, and should identify key areas of nonacceptance and / or possible confliction as a result of specific unit systems.

The problem articulation method (PAM) supports the definition and resolving of socio-technical problems. Moreover, PAM reduces the complexity of a problem by dividing it into units and sub-units and identifying the stakeholders and their roles, recognising openly all interacting systems within a building. PAM allows resource use within a complex building to be viewed holistically, yet facilitates provision of detailed information concerning a chosen focal system, specific objects and / or supporting services; as the semiotic framework places resource use in context of both technical and human KPI. By modelling these dimensions, in context of the defined systems, we are able to monitor live stakeholder activity. In the following section we discuss how a building information model would assist in encouraging sustainable occupant activity.

\section{SEMANTIC BUILDING INFORMATION MANAGEMENT}

As discussed previously, existing methods of assessing building sustainability focus on a limited set of building characteristics; normally measured via a set of criteria or checklists. These methods fail to take into account the details of a building's design, primary usage and occupant behaviour. In order to improve building assessment methods and provide building stakeholders with useful information relating to their particular $\mathrm{KPI}$ context and performance, a semantically rich building model is proposed. 
A semantically rich building model implies a virtual representation of the real-world space, which should ideally include and combine a virtual representation of the building structure and fabric, with information about content objects, activity, and building facilities. Such a model can be used to iteratively consider the building's design, with alignment and consideration of occupant activities and resource performance, and record information and relationships between them throughout the lifespan of either the building, and/or specific care pathways to allow change in policy towards sustainability.

The development of a truly semantically rich model would facilitate a number of valuable benefits, including the ability to assess building performance in greater detail, and accurately compare multiple buildings whilst taking relevant contextual differences into account. Crucially, such a model would also provide building's stakeholders with useful building specific information about activity performance over time, which can be used to inform and motivate individual users and organisational management towards appropriate sustainable change.

\section{Building Information Modelling}

BIM (Building Information Model or Building Information Modelling) is an evolving domain within the construction industry that provides the potential for describing both activity and objects within the given space [31] [32]. There is currently some confusion as to the use of BIM. Companies, such as Autodesk, define BIM is a software application [33] [34]; others consider BIM as a process for designing and documenting building information; others consider BIM as a whole new 
approach to practice and advancing the profession which requires the implementation of new policies, contracts and relationships amongst project stakeholders.' [35]. A 2011 NBS study found that only 12\% of construction professionals feel the industry is clear enough on what defines BIM [36]. In this paper we encourage the integration of all ideas, since we believe that focus on software, process and/or documenation alone does not allow the full benefits of BIM to be realised. Semantic building information modeling and management, therefore, requires a integrated approach, where early involvement of stakeholders from software, process and documentation domains is a norm.

\section{Representing Building Semantics}

In order for our proposed model to support the tracking of detailed information relating to occupant behaviour and resource use, in the context of healthcare buildings, we must first develop a rich and machine-readable semantic building model. A semantic data model contains both facts (i.e. data), but also a description of meaning 'i.e. context' that relates to the specific fact. Since facts can be contextualised, factual data to be collected, analysed and disseminated in a relevant context of use. Such a model, in context of health space, would need to include key design concepts, such as spaces, walls, windows and resourceconsuming appliances. Relationships between these concept types are also

critical in order to allow software to make contextual decisions and perform 
automated functions based upon the structural relationships between building objects.

3D parametric modelling of buildings has been developed incrementally over three decades. It has evolved into building information modelling (BIM) [37], and can support a wide range of visualizations designed to visually present building information to a range of building stakeholders; although used primarily by building management and facilities staff. Much work has been devoted to systems for concurrent engineering and design collaboration [38]. The 4D CAD concept [39], in which 3D building models are 'animated' by linking them to construction schedules that provide the fourth dimension, has been adopted in industry and commercial applications are available for 4D construction planning, such as CommonPoint and Synchro. Akinci et al. [40] demonstrated how work spaces and temporary facilities could be generated and added to 3D building design models to enable evaluation of construction plans for space conflicts. Some systems incorporate cost as a 'fifth dimension' of project information and aim to enable 'virtual construction'. Among the small scope of visualisation research that deals with day to day operations onsite are applications of virtual reality [41] and augmented-reality [42].

Parametric modelling needs to be supported by common standards that enable integrated work and exchange of information. Several standards are in existence today which support the modelling process. BS 1192, for instance, provides the methodology for managing the production, distribution and quality of construction information. This is achieved by using a disciplined process for collaboration and 
a specified naming policy (BSI). A wide selection of standard classification systems like SfB, BSASB, Cl/SfB, Uniclass, Building 90, OmniClass, DBK support data exchange between construction projects stakeholders. PAS55, or a Publicly Available Specification (PAS) published by the BSI British Standards was developed in response to industry demand for an asset management standard. However, it is the model itself that sits at the core of the virtual construction efforts and Industry Foundation Classes (IFC), which represent the main data model standard. IFC has been developed by BuildingSmart (formerly known as the International Alliance for Interoperability) [23]. IFC is a relational and object-based model that allows designers to develop 3D building semantic models, which supports the explicit linking of semantics to objects. Rather than basic shapes being used to draw the outlines of walls and relying on human users to interpret lines correctly, a set of lines within an IFC model are explicitly listed as a specific object. Such objects can include common attributes, such as materials, as well as relationships with other objects. A window object, for instance, is related to a 'window opening' object that is, in turn, related to a wall object. This allows the IFC object model to explicitly define spaces and their bounding walls, allowing us to represent a relationship between a room and its current occupants and contents.

\section{Representing Occupant Behaviour and Resource Efficiency}

Once a basic building information model is in place, we can link the model to existing BMS (Building Management Systems) data and extend the model to 
map people, activities and resource use information within the model. The capabilities of the IFC object model do not currently cater for the inclusion of complex dynamic and temporal data streams [24]. It would therefore be necessary to export and extend the IFC dataset so allow designers to add further concept types and relationships to support information about occupants, activities and energy usage. To allow this we propose the use of either a relational or entity attribute value (EAV) based database that allows the model to benefit from complex analysis and querying of contained data. EAV should be considered if complex behaviour or temporal modelling is required.

By analysing model data, we are able to establish relationships between specific occupants, activities that they perform, the spaces they typically occupy during their stay in the building and the energy resources that they consume. This information can be used to provide detailed behaviour feedback to users, and would highlight poor performers, and would support users in identifying how activity could be best re-engineered towards sustainability. In the following section we provide discussion concerning the use of persuasion, and how persuasive models may be used in conjunction with model information to motivate building occupants to motivate user activity towards sustainability.

\section{OCCUPANT PERSUASION}

Within hospitals, the largest consumer for energy/resource is heating (see figure 3). Although monitoring air temperature data, and energy consumption, in the building information model would allow us to understand and draw 
conclusions concerning the relationships between energy consumption and thermal comfort criteria [30], appreciating these relationships does not in itself inform stakeholder activity.

Although the temperature in health building must remain within comfort limits, use of heating in hot weather, and/or in the same space as fixed or mobile air-conditioning, or simply leaving a window or door open in winter is an activity that could lead to significant resource implications.
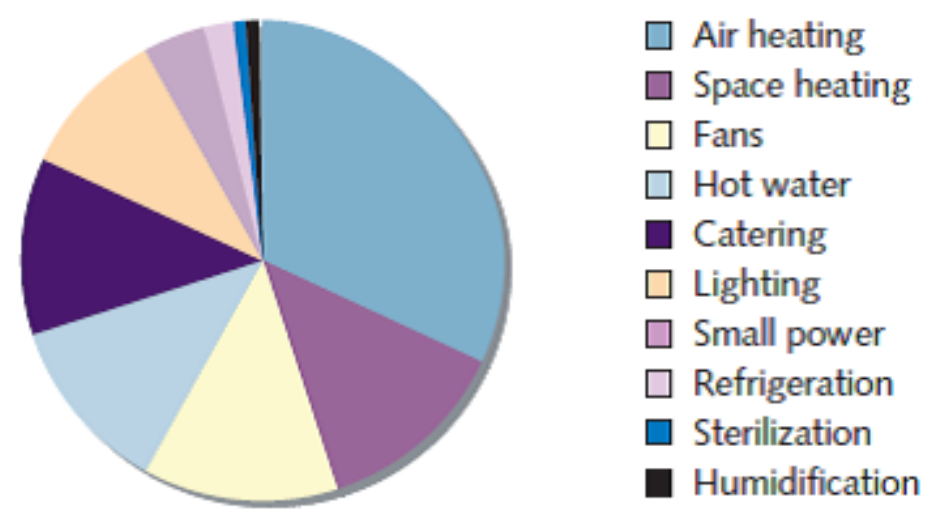

Figure 3: Energy use - data from Bradford Royal Infirmary, Cambridge Addenbrookes, St Albans City and Leicester Glenfield [30].

A number of studies have considered how user persuasive mechanisms can be used as a method for reducing resource consumption. Within the context of low-complexity buildings, e.g. care homes, [10] [11] and [12] looked at the issue of energy feedback. These studies supported the definition of specific goals, and offered a range of feedback modes, yet none of these studies validated resource saving and/or considered saving in context of user activity. Feedback in large and complex buildings, such as hospitals, is significantly more complex; and a number of studies have considered multi-user buildings. [12] and 
[13] undertook short term studies considering the issue of energy management within large University halls of residence. [14] and [15] conducted longer duration studies (i.e. respectively 1.5 - 4 months) looking at energy feedback in commercial buildings. These studies show that large buildings have a considerable potential for resource saving, with results impacted by the type of activity within the building, the nature of users, and the type of motivation used to persuade users toward positive behaviour. Within care and health space, understanding user behaviour (both patient and clinician), and providing users with relevant information and persuasive motivation mechanisms and triggers to adopt sustainable activity, seems critical in achieving long-term sustainability goals. Moreover, if behaviour management can be achieved, whist maintaining care quality, good practise norms can be defined to help organisational level policy definition.

Research in the area of persuasive technologies shows that there are multiple means of changing user behaviour. Fog [25] describes three core motivators, i.e. pleasure/pain, hope/fear, acceptance/rejection, which can strongly influence the relationship between users' current activity and attitudes. Fogg [25] stipulates that a change in user behaviour occurs at the moment at which the user has sufficient motivation, i.e. feels able to make the change; which often occurs as a result of external triggers acting on the individual. Semiotics enables modelling and definition of stakeholder behaviour, and by providing relevant stakeholders with appropriate feedback / information we can manage persuasive triggers (often defined as norms); supporting changes 
towards target behaviour. We propose the use of the 3D-RAB persuasion model [26] to support persuasive feedback (management), which requires the assessment of: current behaviour (CB), attitude towards target behaviour (ATTB), attitude towards change (ATCMB).

The 3D-RAB model [26] allows us to categorise users into eight category states as a result of their CB, ATTB and ATCMB. Table 1 show how states are either stable or unstable, which explains how users in unstable states can traverse states as a result of persuasive feedback influencing triggers. In states 1-4 (see Table 1) the user is already performing the target behaviour. Feedback, therefore, should aim to move the user towards, or keep the user in state 1 (i.e. positive action and attitude, low dissonance). If current behaviour is in states 5-8, then user activity change is required.

Table 1: Definition of current behaviour (CB), attitude towards target behaviour (ATB), attitude towards change / Maintaining behaviour (ATCMB) and its impact of dissonance.

\begin{tabular}{|c|c|c|c|c|c|c|c|}
\hline State & CB & ATB & ATCMB & $\begin{array}{c}\text { Cognitive } \\
\text { Dissonance }\end{array}$ & $\begin{array}{c}\text { Stability of } \\
\text { state }\end{array}$ & $\begin{array}{c}\text { Natural } \\
\text { State } \\
\text { tendency }\end{array}$ & $\begin{array}{l}\text { Targeted state } \\
\text { for Persuasion }\end{array}$ \\
\hline 1 & + & + & + & No & Stable (+) & 1 & 1 \\
\hline 2 & + & + & - & weak & Unstable (+) & 1 & 1 \\
\hline 3 & + & - & + & moderate & Unstable (-) & 7 & 1 \\
\hline 4 & + & - & - & Strong & Unstable (-) & 8 & 2 or 3 \\
\hline 5 & - & + & + & Strong & Unstable $(+)$ & 1 & 1 \\
\hline 6 & - & + & - & moderate & Unstable (-) & 8 & 2 or 5 \\
\hline 7 & - & - & + & weak & Unstable (-) & 8 & 3 or 5 \\
\hline 8 & - & - & - & No & Stable (-) & 8 & 4 or 6 or 7 \\
\hline
\end{tabular}


This change can be facilitated by via feedback, either directly to users or, depending on the user state and level of dissonance, to authority stakeholders (i.e. company or building managers). Feedback to authority stakeholders can influence external triggers (e.g. loss of bonus, or management enforced process change), which can increase user cognitive dissonance against positive change. It is the aim of persuasive technologies to ascertain persuasion routes towards state 1 (positive attitude, positive behaviour, positive motivation to maintain behaviour). The relationship of, and transition route of users between states, is based on the theory of cognitive dissonance; which is defined as being: i) strong, ii) moderate, iii) weak or iv) absent. The theory of cognitive dissonance proposes that action and attitude should be aligned or the stakeholder experiences an unpleasant psychological tension [28]. He explained that people adjust their attitudes or behaviour to reduce or eliminate the "tension of dissonance". Strong cognitive dissonance is formed when there is a very strong disagreement between one's attitude and current behaviour. This dissonance produces a conflict that encourages a change in attitude and/or behaviour towards a more stable state. When there is a weak or moderate dissonance the disagreement is not likely to be enough to motivate change.

\section{CONCLUSIONS}

Healthcare organisations are increasingly being forced to consider how they can 'obtain sustainability', yet the majority of research concerning 'sustainability', especially in health care facilities, focuses on building energy and on building 
fabric (i.e. infrastructure). As care space facilitates offer a wide range of different functional needs, it is practically impossible to define a generic list of sustainability KPI. To do so risk definition of generic durable-focused resource strategies, which in context of specific buildings, activity and/or stakeholders risks significant negative long-term socio-technical consequences to care provision and patient safety.

This paper has focused on describing three informatics domains (i.e. organisational semiotics, Building Information Modelling and user persuasive modelling) that, if combined, offer a move toward a more holistic view of sustainability; which is the ability to embrace organisational change by engaging in renewal, maintenance, and managed resource sustenance.

In order to meet the challenging carbon targets set by the Government for 2050, the NHS is seriously considering a significant limitation of its estate. Although this is potentially possible, via use of modern diagnostic, therapeutic and communication technology, and is certainly a sustainable strategy, the impact on patient safety and care provision is currently unclear.

The process for selecting Key Performance Indicators (KPIs), for use with performance assessment in organisations, is both technical and complex; yet identification of activity based KPIs allows key stakeholders to be actively involved in the assessment of their own performance, productivity rates, and cost estimation, etc. Only by providing users with information about their activity, and how it impacts sustainability, quality and patient care and safety, will users and management be able to understand resource use in context of health activity. 
We have shown that organisational semiotics can help identify critical stakeholders, KPI that exist in existing organisations, and the value (both positive and negative) that stakeholders encounter as a result of specific systems in care spaces. In addition collateral structuring allows policy makers identify the interaction and dependence of systems; being aware of functional resource needs. A detailed semantic building information model would facilitate real-time information feedback. As well as allowing us to analyse the building fabric, in context of care space activity, information within BIM can be linked to building facilities management and pervasive information provision to decision makers throughout the care space. By allowing the collection of data in building space, current activity can be analysed (across time and care facilities), best practise policy can be proposed. In addition, since negative stakeholder value and poor current activity can be defined, use of persuasive technologies is proposed to support a positive move in attitude and behaviour (both at the individual and organisational level) towards defined targets. By understanding current stakeholder behaviour, attitude, and attitude towards change, and by considering appropriate changes in policy and related motivation (via incentives and disciplinary action) a pathway can be defined through pervasive states towards a stable positive state of positive behaviour.

Although much needs to be done to realise such a system, it is clear that socio-technical consideration in resource allocation is critical in order to optimise sustainability. Care space is more than a building; with a complex web of sociotechnical systems impacting total resource use. Without considering the impact 
of such systems, integrating socio-technical factors within a building information model, effective user feedback concerning the impact of activity is unachievable. Without feedback, policy definition within and across care facilities is hard to justify; and the link between such policy on resource cost, patient safety and care quality is hard to validate.

\section{REFERENCES}

[1] NHS England Carbon Emissions; Carbon footprint study, 2008. Cambridge: Sustainable Development Unit, Sustainable Development Commission \& Stockholm Environment Institute.

[2] The Energy Performance of Buildings (Certificates and Inspections) (England and Wales) Regulations, 2007. London: HMSO.

[3] A. Haapio, P. Viitaniemi, A critical review of building environmental assessment tools, Environmental Impact Assessment Review, 28(Oct.), 2008, pp. 469-482.

[4] J.G. Fisher, How to Improve Performance through Benchmarking? London: Kogan, 2006.

[5] BREEAM guidance from $\mathrm{DH}$ [Online] Available at:

http://www.dh.gov.uk/en/Managingyourorganisation/Estatesandfacilitiesman agement/SustainableDevelopment/DH_4119587 [Accessed: 27 November 2012]

[6] A. Sabapathy, S.K.V Ragavan, M. Vijendra, A.G. Nataraja Energy efficiency benchmarks and the performance of LEED rated buildings for Information 
Technology fa- cilities in Bangalore, India. Energy and Buildings, 2010, 42(11), pp. 2206-2212.

[7] The Energy Performance of Buildings (Certificates and Inspections) (England and Wales) Regulations, 2007. London: HMSO.

[8] Foresight's Sustainable Energy Management and the Built Environment (SEMBE) Project. Presentation on 24th April 2009. From www.foresight.gov.uk - accessed 5th June 2010.

[9] D.J.C. MacKay, Sustainable Energy - Without the Hot Air, Efficient electricity use, UIT Ltd, 2008, pp. 155-157.

[10] M. Iyer, W. Kempton, C. Payne,Comparison groups on bills: automated, personalized energy information, Energy and Buildings 38(8), 2006, 988996.

[11] G. Wood, M.Newborough, Energy-use information transfer for intelligent homes: enabling energy conservation with central and local displays, Energy and Buildings 2007, 39 (4), pp. 495-503.

[12] S. Karjalainen, Consumer preferences for feedback on household electricity consumption, Energy and buildings, 2011, 43(2-3), pp. 1-13.

[13] G. Peschiera, J.E.Taylor, J.A. Siegel, Response-relapse patterns of building occupant electricity consumption following exposure to personal, contextualized and occupant peer network utilization data, Energy and Buildings, 2010, 42 (8), 1329-1336.

[14] S.H. Hsieh, R.S. Shiu, S.R. Ye, H.M. Chen, C.SChen, On effectiveness of public paper-based information feedback for persuading energy saving in 
an office building environment, Proceedings of the Twenty-Third KKCNN Symposium on Civil Engineering, November 13-15, Taipei, Taiwan.

[15] A.R. Carrico, M.Riemer, Motivating energy conservation in the workplace: an evaluation of the use of group-level feedback and peer education, Journal of Environmental Psychology, 2011, 31 (1), pp. 1-13.

[16] D. Eaton, Benchmarking.In J. Kelly, R.Morledge, and S. Wilkinson (Eds.), Best Value in Construction. London: Blackwell Publishing, 2002, pp. 59-76.

[17] R. K. Stamper, Signs, Information, Norms and Systems, in Holmqvist B et al. (eds.), Signs at Work, De Gruyter, Berlin, 1994, pp. 349-397

[18] R. K. Stamper, K. Liu, M. Hafkamp, and Y. Ades, Understanding the roles of signs and norms in organisations - a semiotic approach to information systems design. Behaviour \& Information Technology, 2000, 19(1), pp. 1527

[19] K. Liu, Semiotics in Information Systems Engineering, Cambridge University Press.UK, 2000.

[20] K. Liu, L. Sun, S. Tan. Using Problem Articulation Method to Assist Planning and Management of Complex projects, in CharrelP. $\mathrm{J}$ and Galarreta, D. (Eds.)Project Management and Risk Management in Complex Projects: Studies in Organisational Semiotics.Springer, Netherlands, 2007, pp. 1-14.

[21] R.K. Stamper, 1973, Information in Business and Administative Systems, New York, John Wiley and Sons.

[22] K., Liu, L. Sun and S. Tan. Modelling complex systems for project planning - 
A semiotics motivated method. International Journal of General Systems, 2006, 35 (3),pp.313 - 327.

[23] Building Smart web site, Model - Industry Foundation Classes. From http://buildingsmart.com/standards/buildingsmart-standards/ifc - accessed 10th Oct. 2011

[24] L. Khemlani, The IFC building model: A Look Under the Hood, AECBytes Features, From http://www.aecbytes.com/feature/2004/IFCmodel.html accessed 12th Oct. 2011.

[25] B. Fogg, A Behaviour Model for Persuasive Design, in 4th International Conference on Persuasive Technology, Claremont, California, ACM, New York, NY, USA, Article 40, 7 pages, 2009.

[26] I. Wiafe, K. Nakata, S.R. Gulliver, Designing Persuasive Third party Applications for Social Networks: The 3D-Bar Model, International Workshop on Social Computing, Network, and Services (SocialComNet 2011), Crete, 2011.

[27] E. Aronson, Back to the Future: Retrospective Review of Leon Festinger's"A Theory of Cognitive Dissonance", The American Journal of Psychology, 1997, 110, pp. 127- 137.

[28] J. Brehm, A. Cohen, Explorations in cognitive dissonance, Wiley New York, 1962.

[29] M. Gottdiener, Postmodern Semiotics - Material Culture and the Forms of Postmodern Life, Oxford, Blackwell. 1995.

[30] L. Fifield, W1LP6 - Monitoring and Modelling UK hospital energy 
consumption to identify optimal building-specific retrofit measures for a changing climate, Loughborough University, Available at: http://www.lolo.ac.uk/project/view/type/phd/project/52 (viewed on 31st of January 2013).

[31] C.M. Eastman, I. Panushev, R. Sacks, M. Venugopal, V. Aram, R. See, A Guide for Development and Preparation of a National BIM Exchange Standard, Technical Report, PCI, Charles Pankow Foundation, Georgia Tech, Technion, 2011

[32] B. Succar. Building information modelling framework: a research and delivery foundation for industry stakeholders Automation in Construction, 18 (3) (2009), pp. 357-375

[33] AutoDesk. [Online] Available at: http://usa.autodesk.com/

[34] Nemetschek VectorWorks, [Online], Available: http://www.vectorworks.net/

[35] Aranda-Mena, Guillermo, et al. "Building information modelling demystified: does it make business sense to adopt BIM?." International Journal of Managing Projects in Business 2.3 (2009): 419-434.

[36] Barlish, Kristen, and Kenneth Sullivan. "How to measure the benefits of BIM-A case study approach." Automation in Construction 24 (2012): 149-159.

[37] Eastman, Chuck, et al. Frontmatter. John Wiley \& Sons, Inc., 2008.

[38] Aspin, R. (2007). Supporting collaboration, in colocated 3D visualization, through the use of remote personal interfaces. Journal of Computing in Civil Engineering, 21(6), 393-401. 
[39] McKinney, K., \& Fischer, M. (1998). Generating, evaluating and visualizing construction schedules with CAD tools. Automation in construction, 7(6), 433-447.

[40] Akinci, B., Fischen, M., Levitt, R., \& Carlson, R. (2002). Formalization and automation of time-space conflict analysis. Journal of Computing in Civil Engineering, 16(2), 124-134.

[41] Fard, M. G., \& Peña-Mora, F. (2007). Application of visualization techniques for construction progress monitoring. Computing in civil engineering 2007, 27.

[42] Behzadan, A. H., \& Kamat, V. R. (2007). Georeferenced registration of construction graphics in mobile outdoor augmented reality. Journal of Computing in Civil Engineering, 21(4), 247-258.

[43] Lee S., Dilani A. Morelli A., Byun H. (2007) Health supportive design in elderly care homes: Swedish examples and their implication to Korean counterpartsm Archives of Medical Research, 9(10), 9-18) 